\title{
A intervenção teatral e a construção de subjetividades no espaço escolar
}

DOI: https://doi.org/10.22409/pragmatizes.v12i22.51091

Luciane Leipnitz $^{1}$

Edilza Maria Medeiros Detmering ${ }^{2}$

Edilza Maria Medeiros Detmering ${ }^{2}$

Elisângela Bruce da Silva ${ }^{3}$

Mariana de Andrade Barbosa ${ }^{4}$

Uliana Gomes da Silva ${ }^{5}$

Resumo: Este artigo apresenta reflexões sobre a intervenção teatral realizada no ano de 2019, em uma escola pública da cidade de João Pessoa, Paraíba, dentro da proposta do Setembro Amarelo (campanha de prevenção ao suicídio). A intervenção da Cia. Artística Alotropicus, em parceria com o projeto extensionista Janelas da Interculturalidade da Universidade Federal da Paraíba, buscou promover a reflexão e o diálogo a partir de atividades cênicas que pensassem a valorização da vida. Para contextualizar o ambiente escolar de realização das ações extensionistas e, mais especificamente, da atividade teatral da Cia., fez-se necessário resgatar e problematizar questões da estrutura da nação brasileira, marcada por desigualdades econômicas, políticas, culturais e sociais. As análises propostas pretendem auxiliar na compreensão do preconceito estrutural no Brasil e pensar o teatro como dispositivo de reflexão, resistência e combate a desigualdades, para buscar o desenvolvimento da cidadania pelo empoderamento do indivíduo e consolidar a democracia. Com este objetivo, o aporte teórico do texto foi construído a partir das contribuições de Augusto Boal (1980, 2002, 2005), Grotowski (1971), Bourdieu $(1996,2003)$ e Paulo Freire $(1987,2000,2006)$ para pensar o teatro e a educação. A apresentação do Projeto contextualiza o ambiente escolar e o grupo alvo das ações desenvolvidas na Escola Chico Xavier. A intervenção teatral se insere neste ambiente e apresenta o bullying em esquete conduzido a partir dos conceitos do Teatro do Oprimido, do Teatro-Fórum e do Teatro Pobre, apresentando a figura do curinga e chamando o alunado à proposição de desfechos para a cena apresentada. Ao final da ação, uma roda de conversa convida à reflexão sobre as escolhas individuais e o respeito ao outro e a sua diversidade. Como conclusão, é possível afirmar que as artes cênicas influenciam as práticas sociais e individuais, no sentido de

\footnotetext{
${ }^{1}$ Luciane Leipnitz, Doutora em Letras pela Universidade Federal do Rio Grande do Sul. Professora Associada, Universidade Federal de Pelotas, Brasil. E-mail: luciane.leipnitz@gmail.com https://orcid.org/0000-0002-7425-2089.

${ }^{2}$ Edilza Maria Medeiros Detmering, Doutoranda em Antropologia, Universidade Federal da Paraíba, Brasil. E-mail: detmering@sti.ufpb.br - https://orcid.org/0000-0002-1693-7661.

${ }^{3}$ Elisângela Bruce da Silva, Licenciada em Letras Língua Portuguesa, Universidade Federal da Paraíba, Brasil. E-mail: elisangelabruce@gmail.com - https://orcid.org/0000-0001-5845-621X.

${ }^{4}$ Mariana de Andrade Barbosa, Graduanda do Bacharelado em Tradução, Universidade Federal da Paraíba, Brasil. E-mail: maryandrade909@hotmail.com - https://orcid.org/0000-0002-7812-309X.

${ }^{5}$ Uliana Gomes da Silva, Doutoranda em Antropologia, Universidade Federal da Paraíba, Brasil. Email: ulianagomes@gmail.com - https://orcid.org/0000-0002-3983-0912.
} 
proporcionar condições para o empoderamento de sujeitos cujos papéis sociais são constantemente questionados e confrontados. O teatro conforma-se como pedagogia e técnica no processo de construção de relacionamentos afetivos e/ou interpessoais, na busca por individuação e pertencimento a um espaço educacional e social.

Palavras-chave: Artes cênicas; Teatro do Oprimido; educação; bullying; valorização da vida.

\section{Intervención teatral y construcción de subjetividades en el espacio escolar}

Resumen: Este artículo presenta reflexiones sobre la intervención teatral realizada en 2019, en una escuela pública de la ciudad de João Pessoa, Paraíba, dentro de la propuesta de Setembro Amarelo (campaña brasileña para prevenir el suicidio). La intervención de la Cia. Artística Alotropicus, en alianza con el proyecto de extensión de la Universidade Federal da Paraíba, Janelas da Interculturalidade, buscó promover la reflexión y el diálogo a partir de actividades escénicas que pensaran en valorar la vida. Para contextualizar el ambiente escolar de las actividades de extensión y, más específicamente, la actividad teatral de la Cia., fue necesario responder y cuestionar preguntas sobre la estructura de la nación brasileña, marcada por las desigualdades económicas, políticas, culturales y sociales. Este análisis tuvo el objetivo de ayudar a comprender el prejuicio estructural en Brasil y pensar en el teatro como un medio de reflexión, resistencia y combate a las desigualdades, buscando la ciudadanía para el empoderamiento del individuo y la consolidación de la democracia. Con este objetivo, el aporte teórico del texto se construyó a partir de los aportes de Augusto Boal $(1980,2002,2005)$, Grotowski $(1971)$, Bourdieu $(1996,2003)$ y Paulo Freire $(1987$, $2000,2006)$ para pensar el teatro y la educación. La presentación del proyecto de extensión Janelas da Interculturalidade contextualiza el entorno escolar y el grupo objetivo para el desarrollo de actividades en la escuela Chico Xavier en João Pessoa, Paraíba, Brasil. En este entorno, hay una intervención teatral y presentación o acoso en una obra teatral basada en de las concepciones del Teatro del Oprimido, el Teatro-Foro y el Teatro Pobre, introduciendo la figura del comodín y llevando a los estudiantes a la basura propuesta para la cena presentada. Al final de la acción, una rueda de conversación invitó a la reflexión sobre las elecciones individuales y el respeto por los demás y su diversidad. En conclusión, es posible afirmar que las artes escénicas inciden más en las prácticas sociales e individuales, sin el sentido de brindar condiciones o empoderamiento de sujetos cuyos roles sociales son constantemente cuestionados y confrontados. El teatro se ajusta a la pedagogía y la técnica en el proceso de construcción de relaciones afectivas y / o interpersonales, en busca de la individualización y el pertenecimiento a un espacio educativo y social.

Palabras-clave: Artes escénicas; Teatro del Oprimido; educación; acoso; apreciación de la vida.

\section{Theater intervention and the construction of subjectivities in the school environment}

Abstract: This paper presents reflections on the theatrical intervention carried out in 2019, in a public school in the city of João Pessoa, Paraíba, Brazil, within the proposal of Setembro Amarelo (Brazilian campaign to prevent suicide). The intervention of Cia. Artística Alotropicus, in partnership with the extension project of the Federal University of Paraíba, Janelas da Interculturalidade, sought to promote reflection and dialogue based on scenic activities that thought of valuing life. To contextualize the school environment in which actions were carried out, it was necessary to rescue and problematize issues related to the structure of the Brazilian nation, marked by economic, political, cultural and social inequalities. The proposed analyzes aims at trying to understand structural prejudice in Brazil and to think theater as a device for reflection, resistance and combating inequalities, in order to seek the development of citizenship through the empowerment of the individual, and consolidate democracy. So, the text was built from the contributions of Augusto Boal (1980, 2002, 2005), Grotowski (1971), Bourdieu $(1996,2003)$ and Paulo Freire $(1987,2000,2006)$ to think about theater and education. The presentation of the Project contextualizes the school environment and the target group of the actions developed at Escola Chico Xavier. The theatrical intervention fits into this environment and presents bullying in a sketch conducted from the concepts of the Theater of the Oppressed (TO), Forum Theater and Poor Theater, presenting the figure of the 
joker, and calling students to propose outcomes for the scene presented. At the end of the action, a round of conversation invites reflection on individual choices and on respect for others and their diversity. Concluding, it is possible to affirm that the performing arts influence social and individual practices, in the sense of providing conditions for the empowerment of subjects whose social roles are constantly questioned and confronted. Theater is pedagogy and technique in the process of building affective and/or interpersonal relationships, in the search for individuation and belonging to the educational and social environment.

Keywords: Performing arts; Theater of the Oppressed; education; bullying; appreciation of life.

\section{A intervenção teatral e a construção de subjetividades no espaço escolar}

\section{Considerações iniciais}

Este artigo apresenta análises sobre a intervenção teatral coordenada pela Cia. Artística Alotropicus ${ }^{6}$ em atividade desenvolvida na Escola Municipal de Ensino Fundamental Chico Xavier, localizada no Bairro Bessa, João Pessoa-PB, Brasil, no mês de setembro de 2019. A ação fez parte das atividades desenvolvidas pelo Projeto de Extensão Janelas da Interculturalidade: ações culturais para o desenvolvimento da cidadania da Universidade Federal da Paraíba (UFPB). A atividade ocorreu a partir de parceria entre o projeto, a escola e 0 grupo de teatro, com o intuito de problematizar e refletir sobre a valorização da vida.

Para o ano de 2019, o Projeto Janelas da Interculturalidade definiu ações mensais integradas aos conteúdos programáticos das disciplinas do currículo regular da

\footnotetext{
${ }^{6} \mathrm{~A}$ atividade do grupo, até o desencadeamento da pandemia de Covid-19, pode ser acompanhada no seu Instagram (https://www.instagram.com/ciaalotropicus/).
}

Escola Chico Xavier. As ações do Projeto foram desenvolvidas no turno da tarde, horário destinado pela Escola às oficinas, e o grupo-alvo foi 0 do $8^{\circ}$ ano. A participação nas ações aconteceu com grupos de cerca de 20 jovens com idades entre 13 e 16 anos. Para a parceria com a Cia. Artística Alotropicus foi organizada uma ação baseada no Teatro do Oprimido (BOAL, 1980), que buscou atuar no enfrentamento de dificuldades identificadas naquele espaço educativo. O mês de setembro, definido para a promoção de atividades de valorização da vida, foi o escolhido para a execução da ação em parceria.

No ambiente escolar, este visto como poder constituído ${ }^{7}$, em que a ação foi desenvolvida, foram identificados, em coexistência, alguns marcadores sociais, que norteiam as

\footnotetext{
${ }^{7}$ O Poder Constituído é descrito como aquele exercido pelos representantes do povo em um ambiente de normalidade institucional, real ou aparente, sempre limitado pelos termos e fundamentos postos pela atividade constituinte (CARVALHO, 2015).
} 


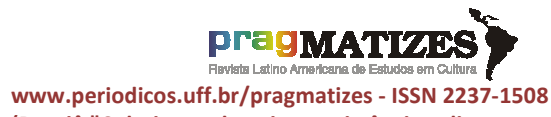

(Dossiê "Coletivos culturais - resistências, disputas e potências") análises apresentadas neste artigo gênero, sexualidade, classe social e, marcadamente, etnia. Por este motivo, é trazida uma breve explanação sobre etnia e a estrutura da nação brasileira - macro contexto no qual a escola se insere.

Auxiliam no desenvolvimento das análises as contribuições de Augusto Boal (1980, 2002, 2005), Grotowski (1971), Paulo Freire (1987, 2000, 2006), Bourdieu (1996, 2003), para citar alguns. A partir deste aporte teórico, as análises deste artigo buscam auxiliar na compreensão do preconceito como estrutural no Brasil e do teatro como dispositivo de reflexão e combate às desigualdades. Após esta reflexão introdutória, o texto traz as características das artes cênicas para apresentar o grupo de teatro que atuou na ação extensionista na Escola, apresenta o projeto de extensão, sua trajetória e as atividades no ano de 2019 com o grupo alvo na Escola Chico Xavier, analisa o contexto em que a atividade foi inserida e destaca alguns dos resultados obtidos, finalizando com considerações que sistematizam as reflexões apresentadas.

\subsection{Reflexões sobre a estrutura}

\section{da sociedade brasileira}

Para contextualizar o ambiente de realização das ações e a atividade desenvolvida na Escola, faz-se necessário abordar algumas das especificidades do macro contexto sociopolítico da nação brasileira. É preciso resgatar e problematizar determinadas questões da estrutura do país (marcado por desigualdades econômicas, políticas, culturais e sociais) e mencionar o fazer teatral enquanto instrumento capaz de proporcionar mudanças individuais $\mathrm{e}$ coletivas.

A estrutura formativa da sociedade brasileira é perpassada por preconceitos e desigualdades que interferem diretamente no processo de socialização dos indivíduos, desnudando questões racistas, homofóbicas, machistas, dentre outras. Essas questões colocam os sujeitos frente a uma realidade marcada por exclusões, sofrimentos sociais e marginalizações. De acordo com Souza (2017), a herança escravocrata abarca esferas econômicas, políticas, culturais e sociais. Ademais, a sociedade brasileira é guiada pelo sistema econômico capitalista, que se caracteriza pela concentração de poder nas mãos de poucos legitimando que $57 \%$ da renda gerada no país concentrem-se nas mãos de $10 \%$ das pessoas mais ricas, segundo a Organização das Nações Unidas (ONU, 2021).

Segundo Almeida (2018), no Brasil, contamos com a produção estrutural do racismo. O autor destaca que a sociedade normaliza no seu dia a dia a atribuição de menores salários às pessoas negras, a ausência destas nas universidades, sujeição a subempregos, não presença nas esferas de poder em posições de destaque, fixação de residência em 


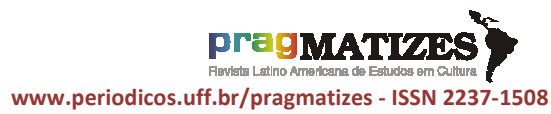

(Dossiê "Coletivos culturais - resistências, disputas e potências") regiões periféricas e perda da vida pelas mãos do Estado (ALMEIDA, 2018, p, 142). Uma sociedade que se diz democrática parece não estender os ideais de fraternidade, igualdade e liberdade para toda a população, pois não cumpre alguns artigos da Declaração Universal dos Direitos Humanos, adotada pela ONU no ano de 1948. Por exemplo, no artigo primeiro, está posto que "todos os seres humanos nascem livres e iguais em dignidade e direitos"; no terceiro, "todo ser humano tem direito à vida, à liberdade, à segurança pessoal" (UNICEF, 1948). Florestan Fernandes (1972) afirma que não se pode falar em democracia racial enquanto não houver igualdade para a população negra dentro da sociedade brasileira. As estruturas racistas alicerçam relações, as quais são cruéis, seletivas e letais.

Em uma sociedade que insiste, cada dia mais, em tirar do armário o racismo (EVARISTO, 2019), é necessário manter-se atento e atuante. A negação de direitos e a legitimação de ideias não apenas racistas, como também machistas, homofóbicas e sexistas precisam ser questionadas e banidas do meio social para que se consiga vivenciar os ideais de uma democracia. Além do fator racial, a Mental Health Foundation (Reino Unido) também afirma que problemas de saúde mental são mais comuns em pessoas LGBTQIAPN $+{ }^{8}$. A discriminação

\footnotetext{
${ }^{8}$ LGBTQIAPN+ é a sigla que engloba pessoas que são Lésbicas, Gays, Bi, Trans,
}

através do racismo e da homofobia geram eventos traumáticos, apontados como fatores que influenciam no desenvolvimento de transtornos mentais.

No Brasil, em 2014, a Associação Brasileira de Psiquiatria (APB), em parceria com o Conselho Federal de Medicina, criou a campanha Setembro Amarelo, propondo prevenir e conscientizar a população contra a morte autoprovocada. Segundo boletim epidemiológico do Ministério da Saúde de $2017^{9}$, estariam entre os fatores geradores de morte autoprovocada: sentimentos de desesperança, desamparo, impulsividade, idade (ressaltando o aumento de casos entre jovens envolvendo motivações como problemas familiares e sociais, negligência e rejeição familiar).

Quando se busca por meio do teatro (especificamente, do Teatro do Oprimido - TO, doravante) verbalizar, ouvir e sentir como as pessoas marginalizadas se sentem frente às estruturas, estruturantes e estruturadas (BOURDIEU, 1996; 2003), o objetivo é fortalecer e contribuir com as lutas de resistência frente a uma sociedade machista, patriarcal, racista e homofóbica. $\mathrm{O}$ teatro possibilita experiências e

Queer/Questionando, Intersexo,

Assexuais/Arromânticas/Agênero, Pan/Poli, Não-binárias e mais.

${ }^{9}$ Mais informações em

https://portaldeboaspraticas.iff.fiocruz.br/wpcontent/uploads/2021/03/2017025Perfilepidemi ologicodastentativaseobitosporsuicidionoBrasil earededeatenaoasade.pdf. 


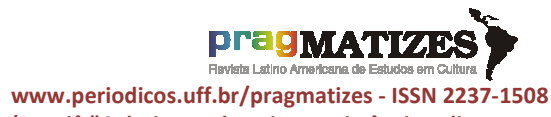

(Dossiê "Coletivos culturais - resistências, disputas e potências") percepções sobre a realidade, diálogos necessários para os enfrentamentos de problemas estruturais da formação brasileira, construindo ligações entre diversos públicos, provocando reflexões e questionamentos sobre as relações sociais, permitindo que um espaço de voz e acolhimento aconteça. Cabe destacar o papel importante do teatro no processo educacional dos indivíduos, sua relação com a educação, que o configura enquanto instrumento para contribuir com 0 desenvolvimento do público a ser alcançado.

\section{O teatro}

O teatro se faz presente na vida humana desde tempos préhistóricos, uma vez que antes mesmo do aparecimento da linguagem, a mímica era responsável pela transmissão do pensamento. Inicialmente, imitando os trejeitos dos animais de seu entorno e, em seguida, fazendo uso de danças e do desenho para narrar seus feitos, os seres humanos usavam seus corpos para teatralizar atividades rotineiras (AIDAR, 1999).

A história do teatro ocidental tem início no século VI a.C. na Grécia, época em que se cultuava o deus mitológico da fertilidade e do vinho, Dionísio. Naquele país, aconteciam festas que duravam muitos dias, com procissões ou ditirambos (canto coral em tom apaixonado, com narração do cantor principal). Da Grécia, a atividade teatral se estendeu para outras sociedades, acontecendo sempre ao ar livre, em um espaço em forma de concha encostado em montes, destinado ao palco e à troca de figurinos (o que hoje se denomina 'camarim') (AIDAR, 1999).

$A$ atividade teatral chegou ao Brasil no século XVI trazida pelos jesuítas com o objetivo de disseminar ensinamentos católicos, passou gradualmente por reformulações, variou em suas expressões, influenciada pelo que acontecia em outros países do mundo. Transportada para espaços fechados, elitizou o seu público. Não se pode pensar o teatro no nosso país sem mencionar Augusto Boal (1931-2009), diretor e dramaturgo, cuja obra é conhecida e aplicada no mundo inteiro. Para ele, "o teatro pode ser uma arma de libertação, de transformação social e educativa" (BOAL, 1980, p. 28). Inspirando-se na filosofia de Paulo Freire, Boal foi o criador do TO, "um sistema de exercícios físicos, jogos estéticos, técnicas de imagem e improvisações especiais, que tem por objetivo resgatar, desenvolver e redimensionar essa vocação humana" (BOAL, 2002, p. 28-29). Boal criou também todas as subdivisões conhecidas do TO, elencadas adiante.

A vocação teatral, como afirma Boal (1980), pertence a todos/todas e não a grupos sociais hegemônicos específicos. A atividade teatral se constitui em "instrumento eficaz na compreensão e na busca de soluções para problemas sociais e interpessoais" (BOAL, 1980, p. 29). A 


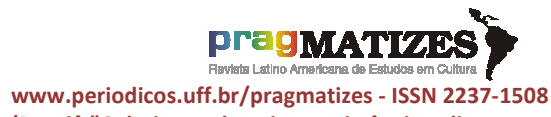

(Dossiê "Coletivos culturais - resistências, disputas e potências") partir do TO, entende-se que a linguagem teatral é a linguagem humana do dia a dia, que cria a condição para que o sujeito oprimido assenhore-se do fazer teatro para expressar seus sentimentos, angústias e quaisquer conteúdos que deseje comunicar, relacionando-se diretamente com seus espectadores. Pode-se entender o TO como um sistema que faz uso de exercícios teatrais para formar e transformar política e esteticamente indivíduos oprimidos em sujeitos, um importante instrumento de formação política a partir dos sentidos produzidos pelas expressões humanas coletivas.

O TO oferece vasto leque de possibilidades, exigindo a criação de grupos para sua aplicação. Podem-se desenvolver técnicas do TO a partir de quaisquer das especificidades a seguir elencadas: Teatro-Jornal, Teatro Imagem, Teatro Invisível, TeatroFórum, Arco-Íris do Desejo, Teatro Legislativo e da Estética do Oprimido. Entre estas, a que recebe destaque neste artigo é o Teatro-Fórum (TF, doravante), por se aproximar da atividade desenvolvida na Escola Chico Xavier. No TF, apresenta-se uma temática em forma de peça teatral, que pode ser um 'modelo' ou 'anti-modelo', sendo o 'curinga' a peçachave para a execução das ações. É o curinga quem explica ao público o que é apresentado no palco, e convida os espectadores a entrarem em cena para performatizar possíveis modificações no ato cênico, e problematizar ou apresentar soluções para a opressão apresentada. O intuito é, segundo Desgranges (2006, p. 70), "ajudar o espectador a se transformar em protagonista da ação dramática, para que, em seguida, utilize em sua vida as ações que ensaiou na cena".

No ato cênico do TO, o sujeito/ator é o detentor da voz, é aquele que coloca em prática suas ideias para superar uma situação que o oprime, em busca de possibilidades que o permitam atuar no seu contexto social. Sendo frequentemente acionado por grupos sociais os mais diversos, o TF vem sendo empregado em empresas, escolas, em coletivos ativistas, para citar alguns espaços. Advêm de seus resultados, o sucesso que alcança em vários países e a frequência com que esse recurso teatral vem sendo acionado.

O desenvolvimento de múltiplas direções do Teatro-fórum em tantos países do mundo determina, inevitavelmente, uma revisão de todos os conceitos, de todas as formas, estruturas, técnicas, métodos e processos. [...] Dentro das múltiplas formas e maneiras de se praticar o Teatrofórum, contudo, surgem muitas dúvidas, mas também muitas certezas (BOAL, 2005, p. 319).

Trata-se de uma forma mais intimista de fazer teatro, derrubando a chamada 'quarta parede'. Além da figura icônica de Augusto Boal, é preciso referenciar Constantin Stanislavski (1863-1938), cujas propostas cênicas são utilizadas por artistas de teatro, cinema e televisão. Seus ensaios e estudos são literatura obrigatória para quem estuda ou é 


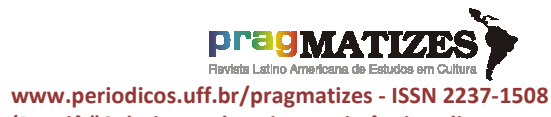

(Dossiê "Coletivos culturais - resistências, disputas e potências") profissional das artes cênicas. Stanislavski foi ator, diretor, pedagogo e escritor russo de grande destaque entre os séculos XIX e XX, que desenvolveu um sistema de preparação de atores que leva seu nome e fundou o Teatro de Arte de Moscou.

Quanto a esse sistema, Benedetti (1988) nos reporta que "não é uma construção teórica, é um processo. Os textos de Stanislavski que possuímos são um guia para esse processo e um convite para vivê-lo direta, pessoal e criativamente" (BENEDETTI, 1988, p. ix, tradução nossa). O autor explica que, para se apreender a atividade mais madura de Stanislavski, é necessário entendê-la enquanto baseada na certeza de que o teatro é um instrumento moral, cuja função é civilizar, aumentar a sensibilidade e a percepção, abrilhantar a mente e elevar o espírito. Um dos mais renomados discípulos e propagadores das teorias de Stanislavski foi Grotowski (19331999), diretor polaco, figura central no teatro do século $X X$ e criador do chamado 'Teatro Pobre' (TP, doravante). Sinceridade e autenticidade são palavras-chave para a proposta de Grotowski.

(O ator) não deve representar para a platéia, e sim se confrontar com ela, em sua presença. Deve cumprir um ato autêntico, tomando 0 lugar dos espectadores, experimentando participar de um ato de extrema sinceridade e autenticidade, ainda que disciplinado. Ele deve doar-se, e não se controlar; abrir- se, e não se fechar, pois isto terminaria no narcisismo. (GROTOWSKI, 1971, p. 169)

A partir das teorizações de Boal e Grotowski foi pensada a atividade teatral no contexto aqui apresentado, no intuito de refletir e problematizar a realidade dos indivíduos, sujeitos e protagonistas de suas vidas. O teatro se apresenta como uma forma de contribuir com o processo reflexivo da condição de sujeito, das opressões provenientes do sistema capitalista, da luta por direitos e das questões ligadas à luta de classe. Ele parte de elementos dessas realidades para a construção de diálogos entre os públicos envolvidos nas apresentações. As reflexões ocorrem no conjunto, pois o processo de libertação não acontece de forma isolada e solitária, "ninguém liberta ninguém, ninguém se liberta sozinho: os homens se libertam em comunhão", alerta Freire (1987, p. 52).

\subsection{O teatro como ferramenta pedagógica}

A escola é reconhecida como um poder constituído, um território que afeta subjetividades e atua na construção de identidades. Cientes da importância do papel que desempenham no espaço escolar, pedagogos, arte-educadores, fonoaudiólogos, psicólogos etc. vêm mobilizando o fazer teatral pelos mais diversos motivos e das mais variadas formas. Este fato pode ser verificado a partir de um breve acesso à Biblioteca Digital Brasileira de Teses e 


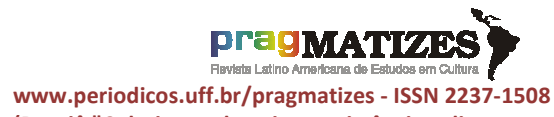

(Dossiê "Coletivos culturais - resistências, disputas e potências")
Dissertações (BDTD) que, com seu vasto sistema de informação, constituise como um renomado repositório de trabalhos acadêmicos, permitindo-nos afirmar que 0 teatro vem se conformando cada vez mais como um sério acessório pedagógico.

A vivência na dramatização de A Farsa de Inês Pereira do autor português Gil Vicente em disciplina cursada no ano de 2017, relatada por Bruce da Silva (2019) em seu Trabalho de Conclusão de Curso (TCC), expressa 0 impacto do teatro na formação profissional, apontando-o como instrumento importante e decisivo para o âmbito acadêmico e para a formação de professores. Essa experiência na trajetória acadêmica veio a fazer parte da própria trajetória de vida, quando a aluna aderiu à Cia. Artística Alotropicus, dois anos após a experiência em sala de aula.

Algumas narrativas da aluna, que interessam à discussão neste artigo, corroboram sua alegação de que 0 teatro foi um dispositivo fundamental na execução de suas atividades acadêmicas. Destacam-se os seguintes trechos de seu TCC: a) "o teatro me proporcionou perder o medo de me expressar e falar em público"; "através da performance, pude ir me aprimorando nas apresentações dos seminários propostos pelos professores"; "pude vencer o bloqueio de falar em público e controlar outros sintomas que vinham junto a ele, como o nervosismo (sudorese, calafrios, etc.)"; "passei a ter resultados mais positivos, boas avaliações dos professores e isso fez com que eu pudesse adquirir mais experiência e solidez nas apresentações, o que foi extremamente importante para minha formação" (SILVA, 2019, p. 23). Esses relatos demonstram quão fundamental e transformadora é a atitude de docentes que utilizam o fazer teatral enquanto instrumento de ensinoaprendizagem. Por fim, em defesa de uma pedagogia que empodere os/as discentes, a graduanda pondera:

$O$ educador que oferece atividades lúdicas como jogos, brincadeiras, leituras compartilhadas, música e teatro desperta em seus alunos motivação, autonomia, confiança e aprendizagem satisfatória e em segundo lugar vem o prazer, curiosidade, responsabilidade $\mathrm{e}$ socialização (SILVA, 2019, p. 11).

Freire (1987) serviu de inspiração para muitos educadores pelo mundo afora, e para arteeducadores também, como o caso de Augusto Boal. Freire (2006, p. 100) defendia a máxima do "não sou se você não é, não sou, sobretudo, se proíbo você de ser", desnudando a verdadeira vocação do ser humano. A reflexão crítica sobre a realidade conduz a problematizações acerca da estrutura formativa social, buscando romper com os processos de alienações que oprimem indivíduos, conduzindo-os à libertação das correntes opressoras e dos padrões da engrenagem capitalista. Essa libertação se dá mediante uma práxis pedagógica que parte da conscientização das pessoas sobre 


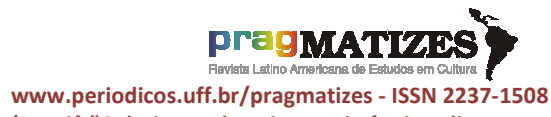

(Dossiê "Coletivos culturais - resistências, disputas e potências") como são conduzidas pelo sistema dominante, entendendo-se que a práxis "é reflexão e ação dos homens sobre o mundo para transformá-lo. Sem ela, é impossível a superação da contradição opressor-oprimido" (FREIRE, 1987, p. 38).

\subsection{Cia Artística Alotropicus - um coletivo artístico cultural}

A Cia Artística Alotropicus desenvolve suas atividades desde 0 ano de 2018, reunindo artistas profissionais e amadores/as. Composta, majoritariamente, por pessoas que frequentam/frequentaram a universidade, a Cia. começou a desenvolver um teatro que poderia ser considerado amador, mas que buscava se profissionalizar. Seu maior desejo é trazer ludicidade para os espaços acadêmicos (ou vinculados a eles), dialogando com o público ali encontrado, ao problematizar questões sociais presentes na cultura brasileira. Mesclando o TO com o TP de Grotowski (1971), já abrigou 12 artistas nesses anos de existência, com apresentações em várias cidades da região metropolitana de João Pessoa-PB e em vários Campi da UFPB. Compõem ou compuseram o grupo professoras, pedagogas, antropólogas, turismólogos, tecnólogos em Redes de Computadores e tradutoras.

As ações desenvolvidas pela Cia. têm sido perpassadas pelas ideias freirianas, buscando dialogar com as realidades, problematizando o modo como se estrutura a sociedade, e objetivando chegar aos sujeitos e provocar reflexões críticas sobre sua condição. Concordando com Freire (2000, p. 85), "onde quer que haja mulheres e homens há sempre o que fazer, há sempre o que ensinar, há sempre o que aprender". A prática teatral conduzida pela Educação Libertadora (FREIRE, 1987) colabora com o processo de construção da consciência crítica (motivada pelos ideais de rompimento da opressão) dos sujeitos sobre a sociedade. Essa prática volta-se para os sujeitos inseridos nas classes populares em que são oprimidos, violentados, que têm direitos negados no meio social, político, econômico e cultural.

A Cia. Artística Alotropicus vem exercendo seu papel educativo em várias atividades e espaços propícios ao fazer teatral, utilizando o TP, que pressupõe a utilização de poucos recursos cênicos, num movimento que coloca o corpo em evidência. Esse corpo é o comunicador da essência e do âmago da personagem a que dá vida. A Cia. já desenvolveu várias ações junto ao $\mathrm{PET} / \mathrm{Conexões}$ de saberes - Acesso e permanência de jovens de origem popular à universidade: diálogos universidade-comunidade, da UFPB (ver Figura 1). Esta iniciativa é responsável por levar educação gratuita e de qualidade a jovens da comunidade paraibana que desejem adentrar a universidade.

Figura 1 - Apresentação da Cia. Alotropicus no Campus I UFPB - João Pessoa/2019. 


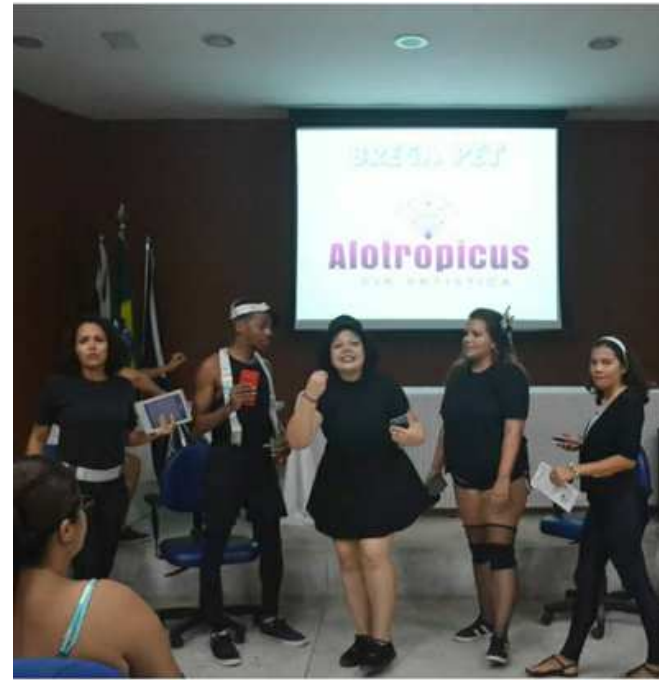

Fonte: Arquivo Cia. Artística Alotropicus.

O PET é desenvolvido por estudantes no formato de grupos tutoriais de aprendizagem, sob a orientação de um professor, organizados em nível de graduação e que consolidam ações extracurriculares orientadas pelo princípio da indissociabilidade entre ensino, pesquisa e extensão. O PET iniciou suas atividades em 1992 e conta com a atuação de oito grupos em diversas áreas do conhecimento. O trabalho desenvolvido tem como objetivo promover a qualificação da educação superior, em sintonia com a formação social e acadêmica científica (SIGEVENTOS-UFPB, 2021).

$$
\text { Cabe frisar que } 0
$$

PET/Conexões de saberes se configura como um espaço de diálogos e de ações frente às necessidades de seu público alvo. Ainda, valoriza os indivíduos envolvidos no processo de construção do projeto e assume um compromisso político-social, objetivando a democratização do saber e do ensino, no que dialoga com os interesses da Cia. Alotropicus.

As ações da Cia. Artística, nos anos de 2018 e 2019, visavam incentivar alunos e alunas de ensino médio ou cursistas do pré-universitário da Educação de Jovens e Adultos (EJA) do PET à preparação para o Exame Nacional do Ensino Médio (Enem). Foram realizadas também apresentações do grupo em outros Campi da UFPB (ver Figura 2).

Figura 2 - Apresentação da Cia. Alotropicus no Campus III UFPB - Bananeiras/2019.

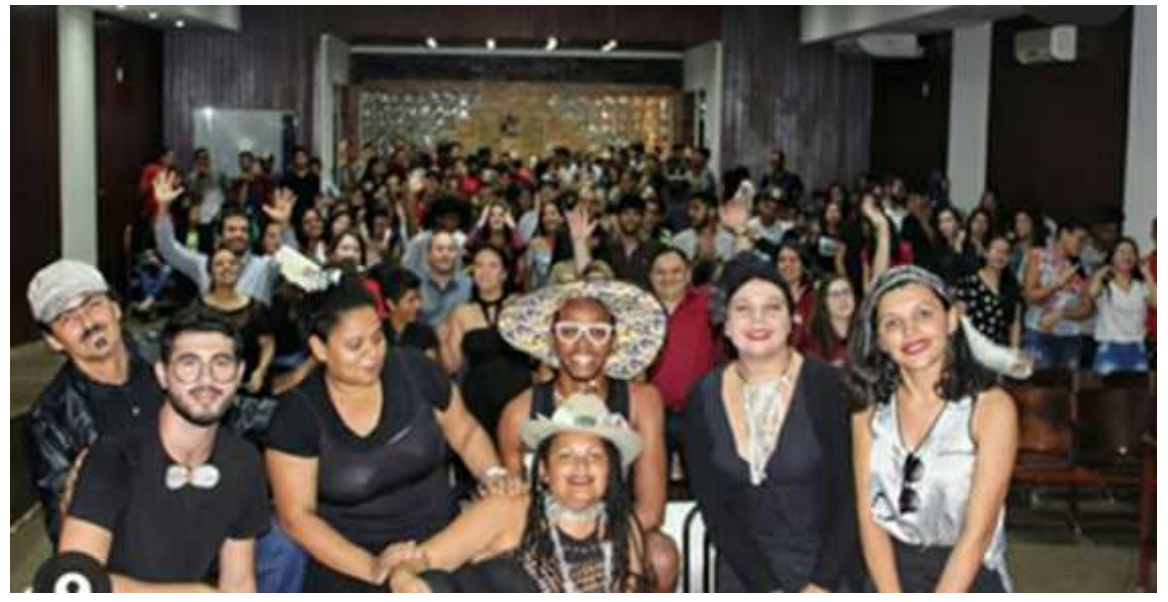

Fonte: Arquivo Cia. Artística Alotropicus. 


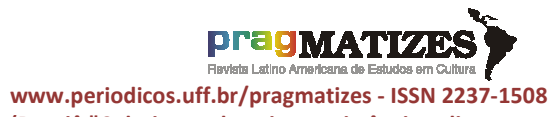

(Dossiê "Coletivos culturais - resistências, disputas e potências")
Ainda no ano de 2019, em parceria com o projeto Janelas da Interculturalidade, a Cia. Artística buscou trabalhar a valorização da vida na Escola Chico Xavier, através de esquetes que abordassem desde questões étnicas às de gênero (já trabalhadas com o PET), demandas identificadas entre discentes, docentes e coordenação daquele espaço pedagógico. Os/as jovens, em processo de descoberta e de afirmação de suas identidades e subjetividades vivenciavam, a partir de seus corpos, conflitos diários tanto no ambiente doméstico quanto no escolar, sendo as ações desenvolvidas no ano de 2019 destinadas a auxiliar a reflexão sobre tais conflitos. A partir dessa compreensão sobre o próprio corpo, percebe-se a atividade teatral em que o corpo é protagonista - como dispositivo de grande importância para se pensar a construção social dos marcadores da diferença, sejam eles etnia, gênero ou outro.

A Cia. Alotropicus surge nesse contexto, mas o ultrapassa e alcança outros espaços. Por exemplo, ao buscar o diálogo com a literatura, criou o projeto Literando, em parceria com um ator e jornalista, seu colaborador. Os encontros de literatura brasileira foram momentos que proporcionaram reflexões, leituras, análises, alcançando um público diversificado. Outro exemplo a ser citado diz respeito a uma apresentação de alguns membros da Cia., alunos de uma disciplina do curso de Pedagogia da universidade. Navalha na carne, peça de Plínio Marcos, foi adaptada para a sala de aula e ganhou proporção além do esperado, devido à elogiada performance daqueles artistas não profissionais. A peça foi então pensada para apresentação no teatro, o que não se concretizou por conta da pandemia (o mesmo acontecendo com os demais projetos da Cia. Alotropicus, que serão retomados no futuro). Tratando-se de pessoas que não vivem do teatro, que são profissionais e estudantes de outras áreas, as ações do grupo foram afetadas pelo contexto pandêmico, escancarando as dificuldades de se fazer arte no nosso país.

\section{O Projeto Janelas da Interculturalidade}

As ações mensais do Projeto de ExtensãoJanelas da Interculturalidade: ações culturais para 0 desenvolvimento da cidadania na Escola Municipal de Ensino Fundamental Chico Xavier, com o grupo do $8^{\circ}$ ano do ensino fundamental, ocorreram no turno da tarde, e a participação do alunado nas ações era voluntária. As 06 (seis) ações, desenvolvidas entre os meses de maio e novembro, buscaram integrar a grade curricular e os conteúdos programáticos para 0 nível/ano escolar.

Buscou-se a integração social entre 0 alunado da comunidade escolar e destes com professores, familiares e amigos, por meio do resgate da cidadania e do acolhimento das diversidades. Por meio da oferta 


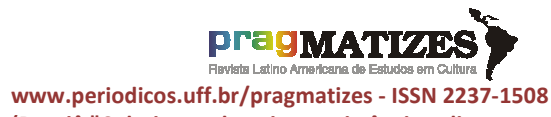

(Dossiê "Coletivos culturais - resistências, disputas e potências") de atividades lúdicas e culturais, o Projeto objetivou apresentar temáticas atuais, presentes no dia-a-dia na Escola, em família e em sociedade, selecionadas a partir de observações e vivências no ambiente escolar, mas também de comentários do alunado nos debates promovidos durante as ações no ano de 2019. O Projeto buscou, através do debate, da conversa informal, conscientizar 0 alunado sobre a necessidade do combate a quaisquer formas de preconceito, por meio da aceitação e do respeito ao outro.

As ações tomaram como ponto de partida a exibição de curtasmetragens de animação, que geraram debates, a partir dos quais foram propostas as atividades do Projeto. Nos três primeiros encontros, trabalhou-se com o tema do não preconceito ao diferente, da aceitação da diversidade física em diferentes contextos sociais. A partir da apresentação de animações que não exibiam diálogos, na primeira ação, propôs-se, na segunda ação, trabalho em grupos com a produção das sequências de fala das cenas dos curtas no formato de histórias em quadrinhos. $\mathrm{Na}$ terceira ação, apresentou-se curta-metragem em língua alemã para abordagem do tema do não preconceito de raça e cor, a partir do qual se buscou identificar diferenças culturais presentes em ditados populares e provérbios relacionados às cores. No encontro do mês de setembro, o tema compreendeu a valorização da vida, com intervenção teatral da Cia. Artística Alotropicus, parceira do Projeto, e posterior trabalho em grupos de alunos para a produção de propostas de desfecho do enredo apresentado. A ação do mês de outubro foi conduzida por outro projeto de extensão parceiro Empoderamento da Mulher - com exibição de curta de animação, debate e apresentação de conceitos-chave relacionados ao machismo. $\mathrm{Na}$ ação final, no mês de novembro, buscou-se o resgate da ancestralidade dos alunos com apresentação de um estudante e músico negro e de um estudante de origem indígena, para conversa informal e roda de música com o alunado.

Questionários aplicados pelo Projeto no início e ao final do desenvolvimento das ações na Escola permitiram subsidiar a condução das atividades, a geração de relatórios e a produção acadêmica por parte de estudantes e professores da Universidade. Estes questionários ofereceram um perfil inicial do alunado (faixa-etária 13-16 anos, a maior parte indicava apenas a figura materna na composição familiar, baixa renda familiar declarada), mas também apontaram problemas que impactavam o alunado a serem contemplados pelas ações do Projeto numa tentativa de amenização de seus efeitos sobre a comunidade escolar.

A participação foi um dos grandes desafios enfrentados pelo Projeto. Dos aproximadamente 40 alunos que compunham a turma do $8^{\circ}$ 


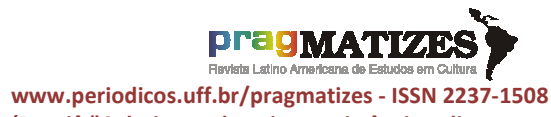

(Dossiê "Coletivos culturais - resistências, disputas e potências") ano da Escola Chico Xavier, apenas de 20 a 27 participaram efetivamente das ações. O contexto socioambiental aparentemente contribuía para 0 esvaziamento das ações. Outras atividades ocorriam simultaneamente e não havia intervenção dos gestores da Escola para incentivar a participação nas ações.

As ações desenvolvidas buscaram integrar diferentes projetos de extensão universitária da UFPB. Integraram também grupos artísticos e culturais da cidade de João Pessoa, na forma de trabalhos em parceria que promovessem o desenvolvimento contínuo de seus participantes pela integração das diversidades e em prol da divulgação de novas possibilidades de expressão alinhadas com propostas multiculturais de acolhimento do outro.

\subsection{Refletindo sobre a ação implementada}

A Cia. Artística Alotropicus se encarregou de preparar uma atividade direcionada a discutir o bullying ${ }^{10}$ no espaço escolar, a fim de conscientizar o alunado sobre as consequências de sua prática. Foram utilizadas diversas técnicas que possibilitaram uma abertura, o chamado 'quebra-gelo', para estabelecer interação e promover confiança no grupo de facilitadores artistas. Estas técnicas teatrais permitiram um primeiro diálogo com o alunado, que possibilitou a oferta de

\footnotetext{
${ }^{10}$ Bullying é um "anglicismo que se refere a atos de intimidação e violência física ou psicológica, geralmente em ambiente escolar" (MEC, 2017).
}

um tema para reflexão e a posterior adesão às problemáticas apresentadas.

Após a exibição de uma cena que representava um caso de bullying, foi aberta uma roda de conversa, com cadeiras dispostas em círculo no centro da sala. É digno de destaque que não se está considerando a intervenção como um exemplo da técnica do TF, uma vez que não foram apresentadas nem desenvolvidas todas as especificidades que esta modalidade contempla. Por ser considerado um dispositivo que favorece a discussão sobre preconceitos, foram utilizadas algumas técnicas do TO para debater a problemática do bullying, que aparecia como queixa do alunado em conversas informais e nos questionários aplicados pelo Projeto.

Participaram dessa ação 27 estudantes, sendo as atividades divididas em dois momentos: i) dinâmica introdutória I - na chegada dos alunos ao auditório da escola, onde eram desenvolvidas as ações do Projeto Janelas. Sentados/as em círculo, todos/as se apresentaram de uma maneira divertida, se dirigindo até o centro e dizendo seu nome, por meio de um gesto/uma ação que demonstrasse uma qualidade ou adjetivo que Ihes representasse, de modo a expressarem a visão que cada qual possuía de si. Esse recurso buscou romper a timidez e propiciar a confiança no grupo de artistas, gerando maior adesão às atividades; ii) dinâmica introdutória II - consistiu 


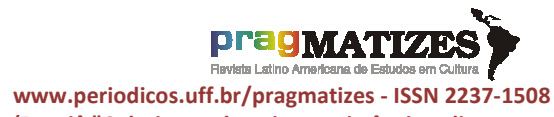

(Dossiê "Coletivos culturais - resistências, disputas e potências") em uma variação da brincadeira de pega-pega (ver Figura 3), cuja mensagem era de que a união os/as fazia mais fortes.

Figura 3 - Dinâmica introdutória II.

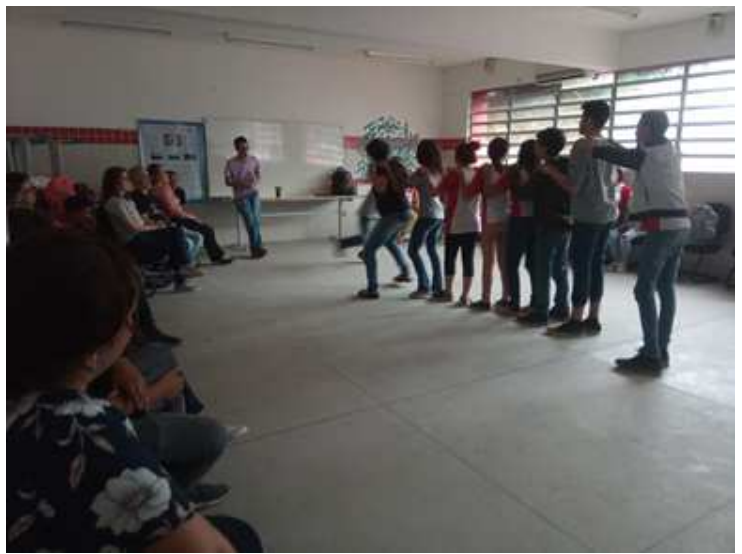

Fonte: Autoria Própria.

A Cia. Artística Alotropicus, contando com a participação de discentes do projeto de extensão da UFPB, encenou uma realidade vivida pelo alunado e, em seguida, abriu debate em que os presentes puderam apresentar experiências e opiniões. A partir deste debate, foram organizados grupos compostos por artistas, alunado e curinga, e cada grupo propôs um desfecho para a realidade encenada. A ideia foi dar espaço, após a reflexão sobre o tema apresentado, para que cada grupo pudesse encenar a realidade da maneira que desejasse.

A peça (um esquete denominado 'modelo', que segue a proposta do TF) mostrava algumas situações de bullying em sala de aula (ver Figura 4). Naquele espaço encenado, algumas alunas eram vítimas de preconceito por conta de sua aparência (no caso, uma das atrizes personificou uma aluna que possuía cabelos crespos e que, por isso, era discriminada pelas colegas) e/ou não respondiam corretamente às várias perguntas feitas pela professora (uma atriz personificou a professora e outra atriz personificou uma aluna que não conseguia responder corretamente às perguntas da mestra, sendo frequentemente repreendida e tornando-se alvo de provocação por parte das colegas).

Figura 4 - Esquete 'modelo' dramatizado pela Cia. Artística Alotropicus.

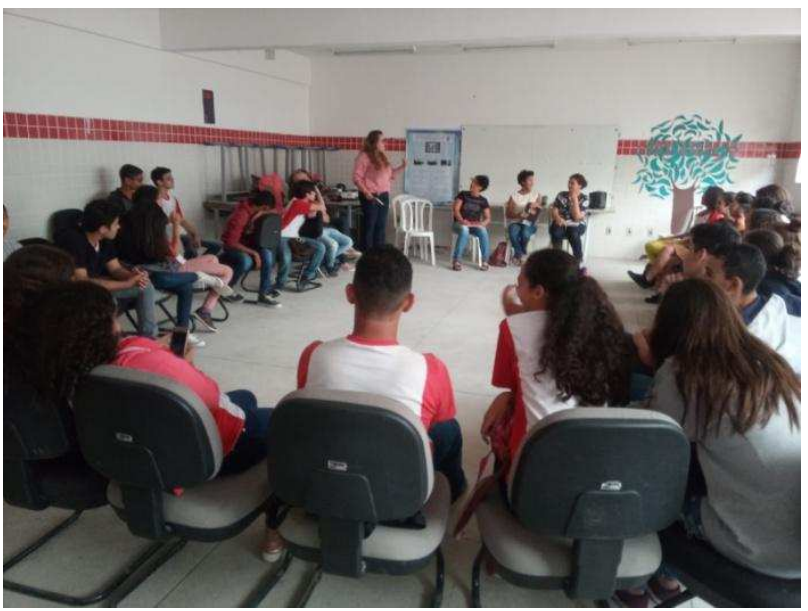

Fonte: Autoria Própria.

O curinga, ator convidado pelo grupo de teatro com experiência em apresentações com o TO, ficou responsável por dirigir a ação e exortar as pessoas a participarem ativamente nas diversas etapas. Após a encenação, curinga, artistas e gestores do projeto dialogaram com o alunado para saber o que haviam entendido do enredo, se concordavam 


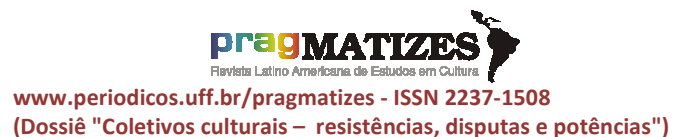

com a atitude da professora e das alunas.

Todas/os que assistiram ao esquete foram convidadas/os a escrever em papéis no formato de maçãs algum conselho, frase ou palavra destinada a quem costuma praticar o bullying. As maçãs portando mensagens foram coladas na 'Árvore dos Desejos', ${ }^{11}$ confeccionada em papel cartolina e afixada (ver Figura 5) no auditório da Escola, local de desenvolvimento das ações. A ideia de utilizar a árvore nesta intervenção surgiu do desejo de dar visibilidade às mensagens produzidas pela turma do $8^{\circ}$ ano. Após a ação, a árvore foi mantida no local e pode ser revisitada pelos/as alunos/as da Escola, prolongando os efeitos da ação daquela tarde.

\footnotetext{
${ }^{11}$ A árvore utilizada nesta intervenção faz alusão a uma fábula de mesmo nome de autoria da escritora Katherine Applegate, publicada no ano de 2020. Nela, a autora mostra a importância do respeito às diferenças e o poder da amizade, da empatia e do afeto, sugerindo que árvores não sabem contar piadas, mas contam ótimas histórias.
}

Figura 5- Alunos/as depositando suas maçãs na Árvore dos Desejos.

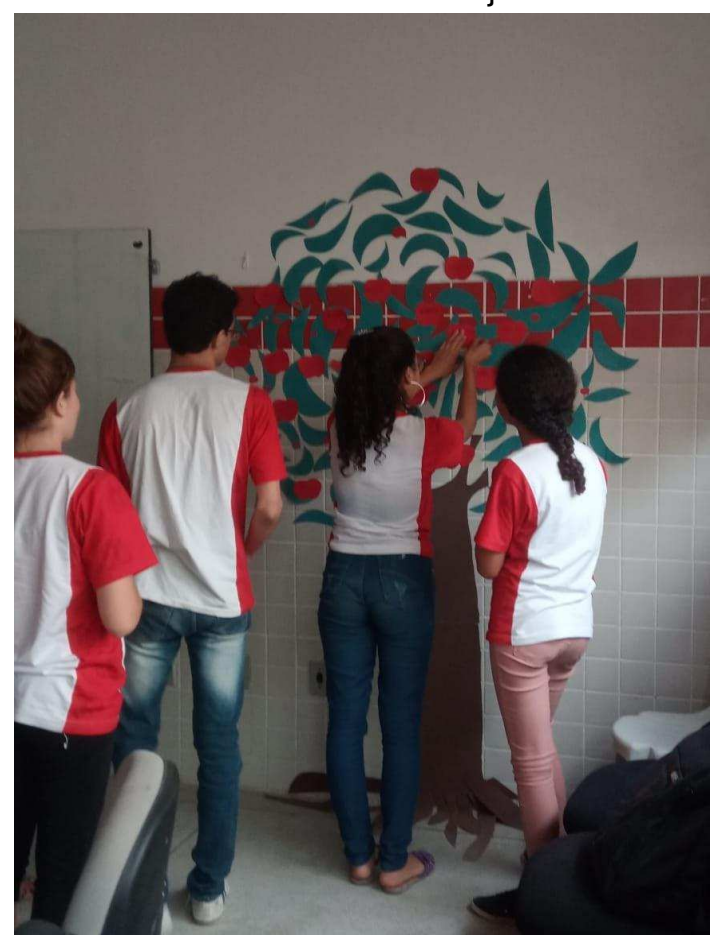

Fonte: Autoria Própria.

$\mathrm{Na}$ etapa seguinte, quem assistiu passou a atuar. A turma foi dividida em grupos de quatro pessoas que, com a ajuda de participantes do projeto, alteraram o final da peça, reconstruíram a história e cada grupo encenou sua versão para os demais. Em geral, as propostas apresentadas não reproduziram a opressão. Quando isto ocorreu, foi por meio da reprovação ao preconceito. Em seguida, puderam avaliar tanto a peça como a atuação dos/das demais colegas. Nessa discussão avaliativa, percebeu-se a ausência do 'perdão'. Nas reconstruções da cena, quem praticava o bullying não pedia perdão a quem machucava, e quem se machucava não perdoava. Discutiu-se 


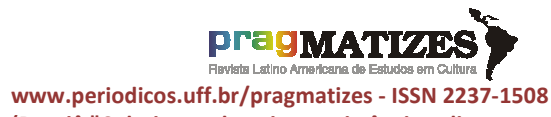

(Dossiê "Coletivos culturais - resistências, disputas e potências") a importância do perdão e, naquele momento, o alunado, por iniciativa própria, se abriu e contou experiências pessoais.

Para encerrar a ação, os/as alunos/as da escola foram convidados/as novamente a escrever para quem sofre ou já sofreu 0 bullying. Escreveram novas mensagens nas maçãs de papel e colocaram-nas na Árvore dos Desejos. A maioria posicionou suas maçãs na copa da árvore, porém uma das adolescentes depositou a sua ao pé da árvore. Quando questionada sobre o porquê de tê-la colocado naquele espaço, ela justificou que era assim que se sentia, isolada, não fazendo parte do grupo, e reportou que já havia sofrido bullying. Toda a proposta da ação se voltou exatamente para a discussão do bullying que, infelizmente, faz parte do cotidiano daqueles/as adolescentes, segundo os diversos relatos registrados.

Acredita-se que a metodologia do TO promoveu o debate de maneira sensível, contribuindo para a valorização da vida e auxiliando na tomada de consciência por parte das/os alunas/os de que são capazes de mudar suas próprias histórias e agir contra uma situação de opressão. Quando foi aberta uma roda de conversa para compartilhar os diálogos, surgiram narrativas que expunham questões de racismo, Igbtfobia e problemas familiares, entre outras questões.

Nesse momento posterior à ação com o esquete teatral, quando da conversa e da exposição das opiniões, as reações das/os alunas/os da Escola foram consideravelmente emocionantes. Os/as participantes queriam falar e serem ouvidos/as. A proposta de cada grupo de alunos/as, que criou soluções para o enredo apresentado pelo grupo de teatro, proporcionou um sentimento de acolhimento, como se uma espécie de portal dentro da realidade silenciosa da escola se abrisse.

Percebeu-se, a partir das falas elencadas, que foi presente a questão do protagonismo. Houve uma reflexão acerca dos problemas discutidos e encenados e da importância dos sujeitos e sujeitas naquele ambiente escolar. Aquela experiência levou o grupo a refletir sobre problemáticas urgentes que surgiam naquele espaço e que não eram discutidas da maneira acolhedora como aconteceu à ocasião. Pode-se considerar que o objetivo do projeto e do grupo de teatro foi alcançado de forma satisfatória, pelo menos no que se refere ao protagonismo das pessoas envolvidas, e cada indivíduo pode, junto com o grupo, buscar novas maneiras de superar e solucionar os conflitos de seu cotidiano.

\section{Considerações finais}

Neste trabalho, apresentou-se a intervenção desenvolvida pela Cia. Artística Alotropicus em sua participação em uma das ações do Projeto de Extensão da UFPB, Janelas da Interculturalidade, no ano de 2019, na Escola Chico Xavier em João 


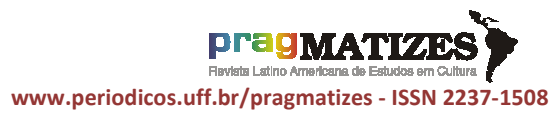

(Dossiê "Coletivos culturais - resistências, disputas e potências")
Pessoa. A partir da apresentação do Projeto, do referencial teórico que embasa a construção e o desenvolvimento das ações da Cia. Artística e do relato da ação desenvolvida na Escola, buscou-se trazer à discussão a inserção de atividades teatrais para a construção de subjetividades no espaço escolar.

No que concerne à prática pedagógica envolvida no desenvolvimento das ações, partiu-se dos princípios norteadores defendidos pelo saudoso Paulo Freire, acreditando-se na necessidade e na importância de diálogos e práticas que valorizem a realidade de cada indivíduo. O perceber e o refletir sobre o contexto no qual se está inserida/o precisam ocorrer de modo crítico, conforme alerta o pensador. Destacam-se também as contribuições de Evaristo (2019), que ajudaram a pensar a intervenção na Escola Chico Xavier, junto ao grupo de alunas/os do $8^{\circ}$ ano, a partir de pressupostos como governamentalidade, racismo e educação. As definições $e$ as propostas do TO foram pensadas a partir das proposições de Boal e de Grotowski, que muito auxiliam a pensar atividades direcionadas ao empoderamento de indivíduos oprimidos ou invisibilizados, e permitiram importantes reflexões sobre o papel do teatro como forma de aproximação às realidades individuais e coletivas não manifestas e como ferramenta para a produção de sentidos, para se combater toda e qualquer forma de preconceito por meio do reconhecimento, da aceitação e do respeito ao outro.

Entende-se que a intervenção apresentada, assim como o trabalho do Projeto Janelas da Interculturalidade desenvolvido no ano de 2019 em escola pública de bairro de classe média baixa do município de João Pessoa, constituiu-se como uma parcela bastante reduzida no amplo espectro das necessidades latentes da sociedade brasileira. Entretanto, percebe-se, a partir da diversidade de propostas de desfechos por parte do grupo de alunos/as e de seus relatos no momento do debate final, o impacto de tais propostas e a necessidade de novas e reiteradas intervenções integradas à realidade escolar como meio de identificação e combate a formas enraizadas de preconceito no seio da sociedade.

As percepções das/os participantes nas ações desenvolvidas naquele espaço - discentes e docentes da UFPB, projetos e grupos culturais parceiros - apontaram a necessidade de incremento de atividades que busquem o combate a qualquer expressão de preconceito. Percebeu-se a necessidade de identificação de realidades específicas, a exemplo do ambiente escolar no ensino fundamental em escola pública em João Pessoa, como forma de construção de uma sociedade mais igualitária, edificada a partir do respeito ao outro, à diversidade e a sua individualidade. Apoiando a reflexão dos pressupostos de Freire (2006), destaca-se: 


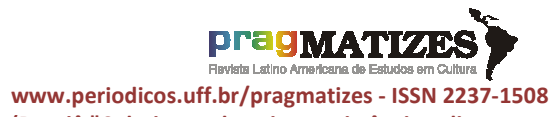

(Dossiê "Coletivos culturais - resistências, disputas e potências")
É preciso que a educação esteja em seu conteúdo, em seus programas e em seus métodos adaptada ao fim que se persegue: permitir ao homem chegar a ser sujeito, construir-se como pessoa, transformar 0 mundo, estabelecer com os outros homens relações de reciprocidade, fazer a cultura e a história (FREIRE, 2006, p. 45).

A atividade teatral - a exemplo do que foi apresentado pela Cia. Artística Alotropicus na Escola Chico Xavier, fundamentando-se nos conceitos de TO e de TP- mostrou-se um importante dispositivo de reflexão sobre a construção de subjetividades, pois contou com o engajamento do alunado nas sugestões de desfecho. Ao final da intervenção, muitas foram as críticas positivas na roda de conversa, a qual gerou ampla discussão sobre situações adversas enfrentadas pelo alunado no seu dia a dia, tanto na Escola quanto em suas residências e em outros ambientes. $\mathrm{Na}$ avaliação final das ações desenvolvidas pelo Projeto Janelas na Escola, tanto alunos/as quanto participantes do Projeto referiram a atividade da Cia. Artística Alotropicus como a que pareceu exercer maior impacto e contar com o maior engajamento de participantes, entre todas as ações realizadas em 2019.

Fica perceptível a conexão entre os princípios e as práticas do TO com a Pedagogia do Oprimido (FREIRE, 1987), uma vez que Freire e Boal partem de ideias que visam um processo de formação de consciência crítica que permita ao sujeito se perceber dentro da realidade da qual faz parte. $O$ desenvolvimento de reflexões críticas sobre o sistema capitalista e as condições opressivas da estrutura social, econômica, política e cultural do país são objetivos das teorias de ambos os autores. O TO contribui com a educação na medida em que possibilita aos sujeitos desenvolverem concepções sobre o poder transformador desta. O teatro é um acessório de combate permanente à insidiosa e preconceituosa sociedade brasileira. Fazer teatro nesse contexto é permitir que os sentimentos que são, em grande parte, influenciados pelos diversos prismas sociais, sejam sentidos, sejam ouvidos. O acolhimento que acontece durante a abordagem teatral também serve como dispositivo de cura.

Os/as alunos/as da Escola Chico Xavier, em resposta ao questionário de avaliação aplicado ao final das ações, no mês de novembro de 2019, ao serem questionados/as sobre o que aprenderam com as ações do Projeto Janelas, apontaram 0 respeito ao próximo e à sua opinião, o respeito às diferenças e às diferentes culturas, a aprendizagem de outros idiomas, a importância e o valor de cada ser humano, independente de cor, raça e gênero, a beleza da diversidade e a importância do conhecimento de nossas origens. Quando questionados/as sobre a permanência do Projeto na Escola no ano de 2020, foram unânimes por sua manutenção. Ao sugerirem 0 que 


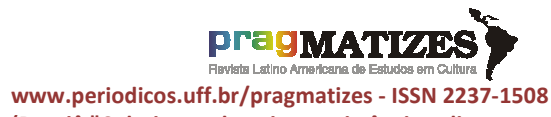

(Dossiê "Coletivos culturais - resistências, disputas e potências") gostariam que o Projeto levasse à Escola, apontaram atividades lúdicas, dinâmicas, de discussão e debate e de atuação $^{12}$.

Tais

$$
\text { apontamentos }
$$

e

constatações devem servir de mola propulsora para a organização e a execução de novas propostas lúdicopedagógicas de inserção de projetos extensionistas e atividades teatrais no ambiente escolar. Tal iniciativa é pensada como forma de resgate $e$ construção da cidadania, a partir da identificação de demandas internas e externas, de informações consistentes, do incentivo à reflexão e ao posicionamento crítico, conduzido com respeito ao outro e à diversidade.

\section{Referências bibliográficas}

AIDAR, Laura. A história do teatro. Toda Matéria [site]. Unesp. 1999. Disponível em: https://www.todamateria.com.br/histori a-do-teatro/. Acesso em: 17 jul. 2021.

ALMEIDA, Silvio Luiz de. O que é racismo estrutural? Belo Horizonte (MG): Letramento, 2018.

APPLEGATE, Katherine. Árvore dos Desejos: Rio de Janeiro: Intrínseca, 2020.

BENEDETTI, Jean. Stanislavski. A biography. NY: Routledge, 1988.

\footnotetext{
12 Em 2020, o Projeto Janelas não pôde dar continuidade à parceria com a Escola Chico Xavier devido à pandemia e ao isolamento social que impactaram sobremaneira a comunidade escolar devido à necessidade de adequação do ensino/aprendizagem ao formato remoto.
}

BOAL, Augusto. Jogos para atores e não atores. Rio de Janeiro: Civilização Brasileira. 2005.

BOAL, Augusto. O arco-íris do desejo: o método Boal de teatro e terapia. Rio de Janeiro: Civilização Brasileira, 2002.

BOAL, Augusto. Teatro do oprimido e outras poéticas políticas. Rio de Janeiro: Civilização Brasileira. 1980.

BOURDIEU, Pierre. A Dominação Masculina. Rio de Janeiro: Editora Bertrand Brasil, 2003.

BOURDIEU, Pierre. Razões Práticas: sobre a teoria da ação. Campinas: Papirus, 1996.

CARVALHO, Harley Sousa. Da relação entre poder constituinte e poder constituído no Estado plurinacional da Bolívia. Revista de Estudos Jurídicos UNESP, Franca, ano 19, n. 30, p. 1-16, ago-dez, 2015. Disponível em: http://seer.franca.unesp.br/index.php/e studosjuridicosunesp/index. Acesso em: 26 jul. 2021.

CFM - Conselho Federal de Medicina. 6.2. Destacam-se outros fatores de risco. 6. Fatores de risco e de proteção: como identificar o paciente suicida. CFM Publicações: Manuais, protocolos e cartilhas. Edição 2014. Disponível em: http://www.flip3d.com.br/web/pub/cfm/i ndex9/?numero=14\#page/14. Acesso em: 28 jul. 2021.

CFM - Conselho Federal de Medicina. 6.Fatores de risco e de proteção: como identificar o paciente suicida. CFM Publicações: Manuais, protocolos e cartilhas. Edição 2014. Disponível em: http://www.flip3d.com.br/web/pub/cfm/i ndex9/?numero=14\#page/12. Acesso em: 28 jul. 2021. 


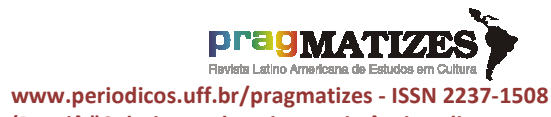

(Dossiê "Coletivos culturais - resistências, disputas e potências")
CIA. ARTÍSTICA ALOTROPICUS. Instagram. Disponível em: https://www.instagram.com/ciaalotropic us/. Acesso em: 20 jul. 2021.

DESGRANGES, Flávio. Pedagogia do Teatro: Provocação e Dialogismo. São Paulo: Ed. Hucitec, 2006.

EVARISTO, Conceição. Cada vez mais o racismo no Brasil sai do armário. [Entrevista concedida a] Carta Capital, São Paulo, 23 março 2019. Disponível em https://www.cartacapital.com.br/cultura /conceicao-evaristo-cada-vez-mais-oracismo-no-brasil-sai-do-armario/. Acesso em: 16 jul. 2021.

FERNANDES, Florestan. O Negro no Mundo dos Brancos. São Paulo: Difusão Europeia do Livro, 1972.

FREIRE, Paulo. Pedagogia da esperança. Rio de Janeiro: Paz e Terra, 2006.

FREIRE, Paulo. Pedagogia da indignação: cartas pedagógicas a outros escritos. São Paulo: UNESP, 2000.

FREIRE, Paulo. Pedagogia do Oprimido. Rio de Janeiro: Paz e Terra, 1987.

GROTOWSKI, Jerzy. Em busca de um teatro pobre. Rio de Janeiro: Civilização Brasileira, 1971.

MEC - Ministério da Educação (Brasil). Bullying. Especialistas indicam formas de combate a atos de intimidação. Disponível em: http://portal.mec.gov.br/ultimasnoticias/211-218175739/47721especialistas-indicam-formas-decombate-a-atos-de-intimidacao. Acesso em: 20 set. 2019.

MHF - Mental Health Foundation. Black, Asian and Minority Ethnic
(BAME) Communities. Reino Unido. Disponível em: https://www.mentalhealth.org.uk/a-toz/b/black-asian-and-minority-ethnicbame-communities. Acesso em: 26 jul. 2021.

MHF - Mental Health Foundation. Mental health statistics: LGBTIQ+ people. Reino Unido. Disponível em: https://www.mentalhealth.org.uk/statisti cs/mental-health-statistics-lgbtiqpeople. Acesso em: 26 jul. 2021.

MS - Ministério da Saúde (Brasil). Secretaria de Gestão Estratégica e Participativa. Painel de Indicadores do SUS. Temático Saúde da População Negra. n. 10, v. VII. Disponível em: https://bvsms.saude.gov.br/bvs/publica coes/tematico_saude_populacao_negr a_v._7.pdf. Acesso em: 28 jul. 2021.

MS - Ministério da Saúde (Brasil). Secretaria de Vigilância em Saúde. Boletim Epidemiológico. n.30, v.48, $2017 . \quad$ Disponível em: https://portaldeboaspraticas.iff.fiocruz.b r/wp-

content/uploads/2021/03/2017025Perfil epidemiologicodastentativaseobitospor suicidionoBrasilearededeatenaoasade. pdf. Acesso em: 26 jul. 2021.

NÓS MULHERES DA PERIFERIA. Site. Disponível em: https://nosmulheresdaperiferia.com.br/ noticias/jurema-werneck-o-racismofaz-com-que-pessoas-negrasadoecam-mais/. Acesso em: 16 jul. 2021.

ONU - ORGANIZAÇÃO DAS NAÇÕES UNIDAS. Brasil. 2021. Disponível em: https://brasil.un.org/pt-br. Acesso em: 20 jul. 2021.

SETEMBRO AMARELO®. Disponível em: https://www.setembroamarelo.com/. Acesso em: 28 jul. 2021. 
SIGEVENTOS - Sistema Integrado de Gestão de Evento. INSCRIÇÃO Processo Seletivo para Professor Tutor do PET Indígena da UFPB. 2021. Disponível em: https://sigeventos.ufpb.br/eventos/publi c/evento/IPSPPTPIU2021. Acesso em: 29 jul. 2021.

SILVA, Elisângela Bruce da. O impacto do teatro e sua influência na formação de professores universitários: um relato de experiência. (monografia de Licenciatura em Letras - Língua Portuguesa). Universidade Federal da Paraíba, João Pessoa, 2019.

SOUZA, Jessé. A elite do Atraso: Da Escravidão à Lava Jato. São Paulo: LeYa, 2017.

UNICEF. Declaração Universal dos Direitos Humanos. 1948. Disponível em:

https://www.unicef.org/brazil/declaraca o-universal-dos-direitos-humanos.

Acesso em: 20 jul. 2021. 